\title{
Lycopene inhibits angiogenesis in human umbilical vein endothelial cells and rat aortic rings
}

\author{
Simone Elgass, Alan Cooper and Mridula Chopra* \\ IBBS, School of Pharmacy and Biomedical Sciences, White Swan Road, University of Portsmouth, Portsmouth PO12DT, \\ Hampshire, UK \\ (Submitted 31 May 2011 - Final revision received 26 September 2011 - Accepted 26 September 2011 - First published online 6 December 2011)
}

\begin{abstract}
Angiogenesis is important for tumour vascularisation and growth, and is therefore a promising target for cancer therapy. The present study reports inhibition of in vitro angiogenesis in human umbilical vein endothelial cells (HUVEC) as well as in rat aortic rings at physiological concentrations of lycopene, that is, $1-2 \mu \mathrm{mol} / \mathrm{l}$. At a final concentration of $1.15 \mu \mathrm{mol} / 1$, a significant reduction $(P<0.05)$ in network branching, that is, junction numbers, the number of tubules and tubule length, was observed in both HUVEC as well as in the rat aortic rings. The inhibitory effect of lycopene was independent of the presence of the pro-angiogenic agents, vascular endothelial growth factor and TNF- $\alpha$. The anti-angiogenic effects of lycopene in the present study were shown at a concentration that should be achievable by dietary means. These results extend our knowledge of one of the putative anti-cancer actions of lycopene.
\end{abstract}

\section{Key words: Lycopene: Angiogenesis: TNF: Vascular endothelial growth factor: Human umbilical vein endothelial cells:} Rat aortic rings

Angiogenesis is one of the prerequisites for tumour growth and progression $^{(1,2)}$. Without the angiogenic process, a tumour can only grow $1-2 \mathrm{~mm}$ in size. Angiogenesis is therefore a potential target in suppressing the spread and growth of cancer. Lycopene (a component of red fruits and vegetables) has been suggested as an anti-cancer dietary component by both epidemiological $^{(3-5)}$ as well as experimental studies ${ }^{(6-9)}$. Various modes of action for lycopene have been suggested for its anti-carcinogenic effects. These range from its antioxidant property $^{(10)}$, reduction in DNA damage ${ }^{(7)}$, inhibition of adhesion, invasion and migration ${ }^{(9)}$, cell cycle arrest $^{(8)}$ and inhibition of tumour growth ${ }^{(6,11)}$. Although each of these modes of action is important for tumour interception, angiogenesis inhibition is considered the most important target for blocking tumour growth. Recently, on subcutaneous implantation of human androgen-independent prostate carcinoma PC-3 cells into athymic nude mice, lycopene at concentrations of 4 and $16 \mathrm{mg} / \mathrm{kg}$ inhibited tumour growth while reducing plasma levels of vascular endothelial growth factor $(\mathrm{VEGF})^{(11)}$. Angiogenic factors such as VEGF, basic fibroblast growth factor and TNF- $\alpha$ are secreted by tumour cells in response to hypoxia and energy depletion, resulting in the recruitment of endothelial cells and their proliferation to mediate angiogenesis and hence tumour growth ${ }^{(12)}$.
In the present study, we have examined the effect of lycopene on angiogenesis in vitro. A number of angiogenesis models have been reported in the literature ${ }^{(13)}$. These assays are based on the formation of tube-like structures, or pseudotubules, from endothelial cells upon their culture on an angiogenesis-supporting matrix. One such substrate is Matrigel ${ }^{\mathrm{TM}}$, which is the trade name for a solubilised basement membrane preparation marketed by BD Biosciences (San Jose, CA, USA). When endothelial cells grow on Matrigel $^{\mathrm{TM}}$, they produce an intricate cell network, which is highly suggestive of the microvascular capillary system that provides tissues with nutrients and oxygen. Structural proteins such as laminin (60\%) and collagen type IV (30\%) make up the bulk of the Matrigel ${ }^{\mathrm{TM}}$ matrix and provide cultured cells with the adhesive peptide sequences they would naturally encounter in vivo. Also containing proteoglycans, heparin sulphate and entactin, the unique composition of Matrigel $^{\mathrm{TM}}$ resembles the mammalian cellular basement membrane and thus provides a biologically active and physiologically relevant environment for studies of cell morphology, migration and angiogenesis. Angiogenesis can also be assessed by way of intricate co-culture of endothelial cells on a feeder layer of fibroblasts in high-priced ready-to-use angiogenesis kits or by using rat aortic rings. The latter, an ex vivo assay, involves thin aortic sections to be cultured on a supportive matrix such as Matrigel $^{\mathrm{TM}}$ and the

Abbreviations: HUVEC, human umbilical vein endothelial cells; VEGF, vascular endothelial growth factor.

*Corresponding author: Dr M. Chopra, fax + 44 2392843565, email mridula.chopra@port.ac.uk 
examination of outgrowth of endothelial and non-endothelial cells over a period of 7-14d. Microvessel outgrowth from these primary explants can be quantified in terms of tubule length and number of junctions within the newly formed network. The rat aortic ring assay closely represents the in vivo environment of angiogenesis, as it involves both endothelial and surrounding non-endothelial cells ${ }^{(13)}$. The present study examines the effect of lycopene on both the above assay systems.

\section{Materials and methods}

All reagents were obtained from Sigma-Aldrich (Gillingham, Dorset, UK) unless otherwise stated. Cell culture reagents were obtained from TCS Cellworks (Little Balmer, Bucks, UK). Matrigel ${ }^{\mathrm{TM}}$ basement membrane preparation was purchased from BD Biosciences. Standard cell culture plastics were obtained from Greiner Bio-one (Stonehouse, Gloucester, UK). Specialised culture plastics were obtained from Integrated BioDiagnostics (ibidi; Martinsried, Munich, Bavaria, Germany). The lycopene powder was a generous gift from DSM Nutritionals (Kaiseraugst, Switzerland).

\section{Culture of endothelial cells}

Pooled human umbilical vein endothelial cells (HUVEC) were obtained from TCS Cellworks and cultured in complete large vessel endothelial cell basal medium supplemented with $2 \%$ complete large vessel endothelial cell growth supplement and antibiotics, as per the manufacturer's recommendations. Cells were passaged using a tailored passage kit, including a buffered rinsing solution, trypsin-EDTA and trypsin blocking solution. Incubation took place at $37^{\circ} \mathrm{C}$ in humidified air containing $5 \% \mathrm{CO}_{2}$. Care was taken not to grow HUVEC beyond $80 \%$ confluence. All experiments involving HUVEC were carried out between passages three and six.

\section{Preparation of lycopene}

Lycopene was prepared fresh for each set of experiments. In short, a lycopene stock solution of $5 \mathrm{~mm}$ was prepared by dissolving the crystalline powder (DSM Nutritionals) in freshly purified tetrahydrofuran with $0 \cdot 025 \%$ butylated hydroxytoluene. Aliquots were stored at $-80^{\circ} \mathrm{C}$ under $\mathrm{N}_{2}$ gas. For experiments, the lycopene stock was diluted in the ratio 1:10 with fetal calf serum for enhanced stability and vortexed vigorously for $1 \mathrm{~min}$. Cells were treated with lycopene at concentrations of $0.58,1.15$ (concentration previously shown to be achievable after the consumption of tomato products for 1 week) ${ }^{(14)}$ and $2.3 \mu \mathrm{mol} / 1$. A tetrahydrofuran toxicity study on HUVEC revealed no effect on cellular viability at tetrahydrofuran concentrations $<0 \cdot 25 \%$.

\section{Rat aortic ring assay}

The twenty-four centre wells of a forty-eight-well microtitre plate were coated with Matrigel ${ }^{\mathrm{TM}}$. A freshly dissected rat aorta was placed in PBS solution and cut into 1-mm rings using sterile scalpel blades in a sterile environment. The rings were then carefully placed into the Matrigel $^{\mathrm{TM}}$-coated wells, one ring per well, and were maintained in Medium 200 containing a low serum growth supplement and $0.3 \%$ of the anti-fungal agent, amphotericin. The plate was then incubated at $37^{\circ} \mathrm{C}$ in $5 \% \mathrm{CO}_{2}$ for $48 \mathrm{~h}$ before treatment. Following $48 \mathrm{~h}$ incubation, the rings were treated with lycopene at concentrations of $0.58,1.15,2.3$ and $5 \mu \mathrm{mol} / 1$ in supplemented Medium 200 in duplicates. Control wells were treated with vehicle only. As outgrowth of cells from the aortic ring occurs over a period of 6-10d and lycopene gradually degrades under cell culture conditions, the treatment medium was refreshed every day.

\section{Analysis of the rat aortic ring assay}

For imaging purposes, the rings were fixed in $10 \%$ phosphatebuffered formalin ( $4 \%$ formaldehyde, $0 \cdot 4 \%$ sodium dihydrogen orthophosphate and $0.65 \%$ disodium hydrogen phosphate) and stained with $150 \mu \mathrm{l}$ of a $0.02 \%$ methylene blue solution for $24 \mathrm{~h}$. The Matrigel ${ }^{\mathrm{TM}}$ was dried under a gentle stream of $\mathrm{N}_{2}$ gas. Images of each well were taken with a FUJI C750UZ digital camera (FUJIFILM Europe GmbH, Düsseldorf, Germany) and pseudotubule outgrowth was analysed using the angiogenesis analysis software AngioSys version 1.0 (TCS Cellworks), which measures tubule length, number of junctions, number of individual tubules and total tubule growth area.

\section{Human umbilical vein endothelial cells monoculture assay}

HUVEC were grown to $50 \%$ confluence and treated with lycopene at concentrations of $0.58,1.15$ and $2.3 \mu \mathrm{mol} / 1$ for $24 \mathrm{~h}$ before seeding onto Matrigel ${ }^{\mathrm{TM}}$; or with TNF- $\alpha$ at concentrations of 5, 10 and $20 \mu \mathrm{g} / \mathrm{l}$ for $24 \mathrm{~h}$ before seeding; or with VEGF at concentrations of 1, 2, 4 and $8 \mathrm{ng} / \mathrm{l}$ upon seeding and for $24 \mathrm{~h}$ before seeding; or simultaneously with lycopene $(0.58,1.15$ and $2.3 \mu \mathrm{mol} / \mathrm{l}$ ) plus $10 \mu \mathrm{g} / \mathrm{l} \mathrm{TNF}-\alpha$ for $24 \mathrm{~h}$; or with lycopene at concentrations of $0.58,1.15$ and $2.3 \mu \mathrm{mol} / 1$ for $24 \mathrm{~h}$, followed by exposure to $8 \mathrm{ng} / \mathrm{l}$ VEGF upon seeding onto Matrigel ${ }^{\mathrm{TM}}$.

After incubation with the test compounds, cells were harvested using $0.02 \%$ EDTA, pelleted by centrifugation and duplicate cell counts were performed. A total of $5 \times 10^{3}$ cells per well were then seeded into the ibidi $\mu$-slide angiogenesis and incubated for $12-24 \mathrm{~h}$. Exposure to $20 \mu \mathrm{g} / 1$ suramine served as a negative control.

\section{Analysis of angiogenesis}

For imaging purposes, pseudotubules were fixed overnight in $10 \%$ phosphate-buffered formalin and pictures of the wells were taken by phase contrast microscopy at overall magnifications of $18.75 \times$ and $30 \times$. The overall length of the tubule networks and the numbers of junctions were determined using the angiogenesis analysis software AngioSys version 1.0 (TCS Cellworks). Good-quality images with a clear contrast of pseudotubules-to-background are required for successful image analysis with this program. Identical 


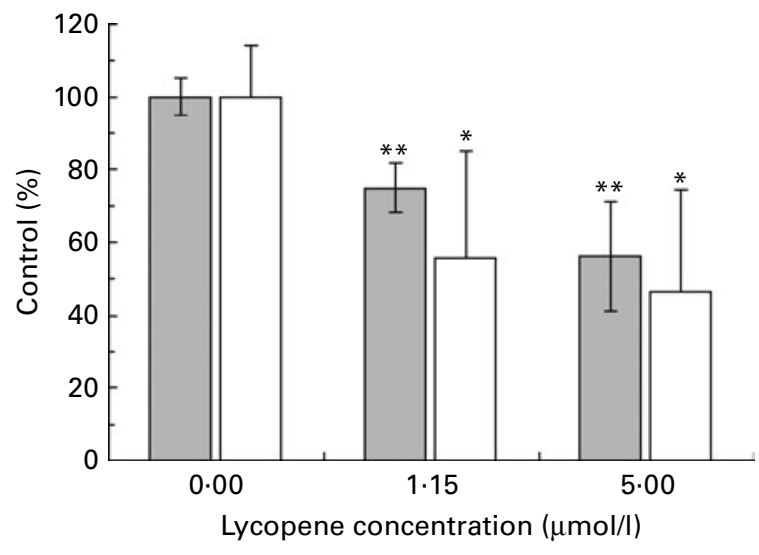

Fig. 1. Tubule length $(\square)$ and junction numbers $(\square)$ of the cell outgrowth of rat aortic rings treated with 1.15 and $5 \mu \mathrm{mol} / /$ lycopene relative to the untreated control $(0 \mu \mathrm{mol} / /$ lycopene). Values are means of three experiments and standard deviations. Mean values were significantly different: ${ }^{*} P<0.05$, ${ }^{\star \star} P<0.01$ (comparison with control was done using a paired $t$ test).

threshold settings were maintained for all images of the same experiment series to ensure accuracy of the results.

\section{Statistical analysis}

Experiments were repeated three times, with triplicate measurements done on each occasion. Results are therefore an average of nine measurements. The data sets were compared by paired $t$ test using SPSS 16.0 for Windows (SPSS, Inc., Chicago, IL, USA), with the significance of difference set at a level of $0 \cdot 05$.

\section{Results}

The rat aortic ring assay closely represents the in vivo environment of angiogenesis, as it involves endothelial cells as well as the surrounding non-endothelial cells ${ }^{(13)}$. Treatment of rat aortic rings with lycopene significantly reduced the pseudotubule network in terms of network length as well as the junction numbers (Figs. 1 and 2). Fig. 1 shows reduction in tubule length by 25 and $44 \%$ with lycopene concentration of $1.15(P=0.04$, paired $t$ test $)$ and $5 \mu \mathrm{mol} / 1(P=0.001)$, respectively. The effect on junction numbers was even more pronounced, with a reduction in network branching of $44 \%$ at $1.15 \mu \mathrm{mol} / 1$ lycopene and a reduction of $43.5 \%$ at the highest lycopene concentration of $5 \mu \mathrm{mol} / 1$. The cell outgrowth at $8 \mathrm{~d}$ after planting the rings is shown in Fig. 2 . The vehicle control (tetrahydrofuran, Fig. 2(a)) shows a nicely structured pseudotubule network with clearly defined tubules and regular branching. All cells appear to be linked into the network, with no apparent cell sheet formation. With the introduction of lycopene into wells (Fig. 2(b)-(e)), the regular network was replaced by a less structured arrangement of cells and greatly increased formation of cell sheets. The lack of structure was most obvious in the well with the highest concentration of lycopene $(5 \mu \mathrm{mol} / \mathrm{l}$, Fig. $2(\mathrm{e}))$, in which seemingly random cell sheets and irregular junctions replaced the defined pseudotubule network observed in the control well (Fig. 2(a)). (a)

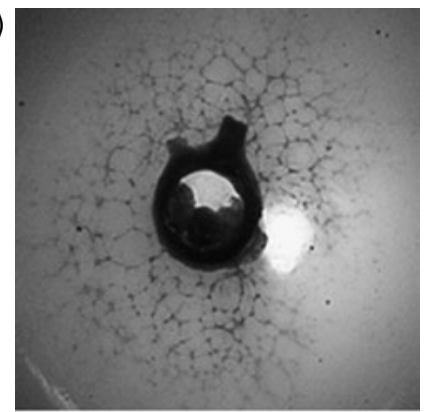

(b)

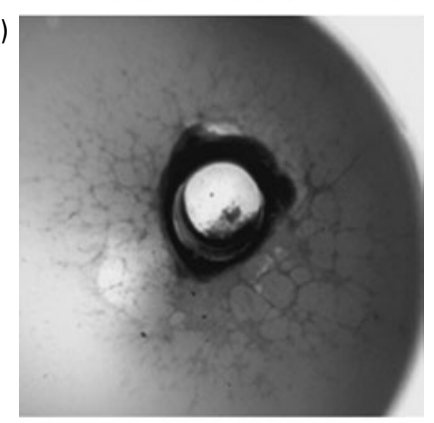

(c)

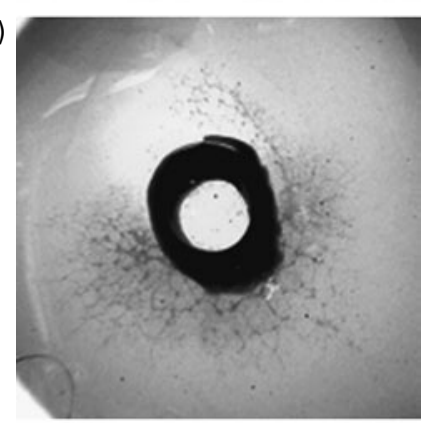

(d)

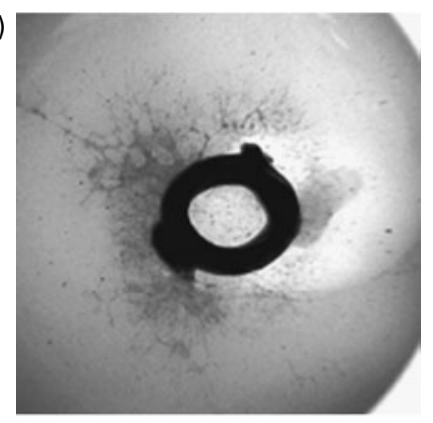

(e)

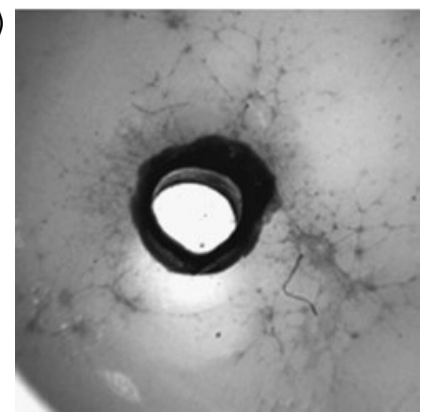

Fig. 2. Rat aortic rings treated with lycopene at concentrations of (a) 0 , (b) 0.58 , (c) 1.15 , (d) 2.3 and (e) $5 \mu \mathrm{mol} / \mathrm{l}$ in tetrahydrofuran. 


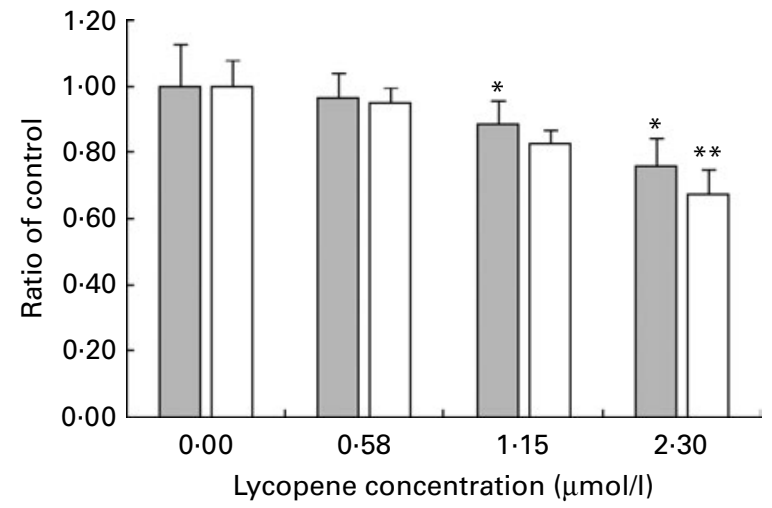

Fig. 3. Effect of lycopene on angiogenesis of human umbilical vein endothelial cells. Cells were treated with increasing concentrations of lycopene for $24 \mathrm{~h}$ before seeding onto Matrige $\mathrm{I}^{\mathrm{TM}}$. The bar chart shows total tubule length ( $\square$ ) and junction numbers $(\square)$ as a percentage of the control values and standard deviations. Mean values were significantly different from control: ${ }^{\star} P<0.05,{ }^{* \star} P<0.01$.

\section{Effect of lycopene on human umbilical vein endothelial} cells monoculture in Matrige/ ${ }^{\mathrm{TM}}$

Fig. 3 shows that with increasing concentrations of lycopene, the overall tubule length of the network as well as junction numbers within this network were reduced. Although the lowest concentration of $0.58 \mu \mathrm{mol} / 1$ lycopene exerted no significant effect, $1.15 \mu \mathrm{mol} / \mathrm{l}$ of lycopene significantly reduced overall network length by $11 \%(P=0.04$, paired $t$ test) and junction numbers by $17 \%(P=0.05)$ compared to the control. The highest concentration of lycopene at $2.3 \mu \mathrm{mol} / 1$ further reduced network formation and junction numbers, resulting in a total reduction of $24 \%(P=0.03)$ and $33 \%(P=0.007)$, respectively. This is also illustrated in Fig. 4, which shows representative images of the tubule network formed by untreated HUVEC (Fig. 4(a)), as well as after exposure of HUVEC to $2 \cdot 3 \mu \mathrm{mol} / \mathrm{l}$ (Fig. 4(b)) and $20 \mu \mathrm{g} / \mathrm{l}$ suramine (Fig. 4(c) - negative control).

\section{Effect of TNF- $\alpha$ and lycopene on angiogenesis}

The effect of TNF- $\alpha$, a known pro-angiogenic factor, alone and in combination with lycopene was assessed. HUVEC were pre-treated with either TNF- $\alpha$ alone or in combination with varying concentrations of lycopene for $24 \mathrm{~h}$ before seeding onto Matrigel ${ }^{\mathrm{TM}}$ in the $\mu$-slide angiogenesis. The initial TNF- $\alpha$ treatment course was used to establish a suitable concentration for HUVEC exposure in combination with lycopene. Cells were exposed to TNF- $\alpha$ at 5, 10 and $20 \mu \mathrm{g} / \mathrm{l}$. Fig. 5(a) shows the effect of TNF- $\alpha$ on overall network length and junction numbers. TNF- $\alpha$ increased both the total tubule length and junction numbers at all concentrations. The latter increased by $14 \%$ at $5 \mu \mathrm{g} / 1 \mathrm{TNF}-\alpha$ and by $18 \%$ at $10 \mu \mathrm{g} / 1(P=0.002)$ of the inflammatory cytokine, whereas tubule length increased by 10 and $16 \%$, respectively. The $20 \mu \mathrm{g} / \mathrm{l}$ concentration of TNF- $\alpha$ did not result in a significant further increase of network formation compared to that at $10 \mu \mathrm{g} / \mathrm{l}$. As a result, the $10 \mu \mathrm{g} / \mathrm{l}$ concentration of TNF- $\alpha$ was used in the subsequent experiments with lycopene.

When cells were exposed to $10 \mu \mathrm{g} / \mathrm{l}$ TNF- $\alpha$ and lycopene simultaneously for $24 \mathrm{~h}$, there was a significant reduction in network branching (junction numbers, number of tubules and tubule length) at both lycopene concentration of $1.15(P=0.05)$ and $2.3 \mu \mathrm{mol} / 1(P=0.01$, Fig. $5(\mathrm{~b})$ and (c)). Lower concentrations of lycopene $(0.58 \mu \mathrm{mol} / \mathrm{l}) \mathrm{did}$ not appear to affect the assessed angiogenic parameters significantly.

(a)

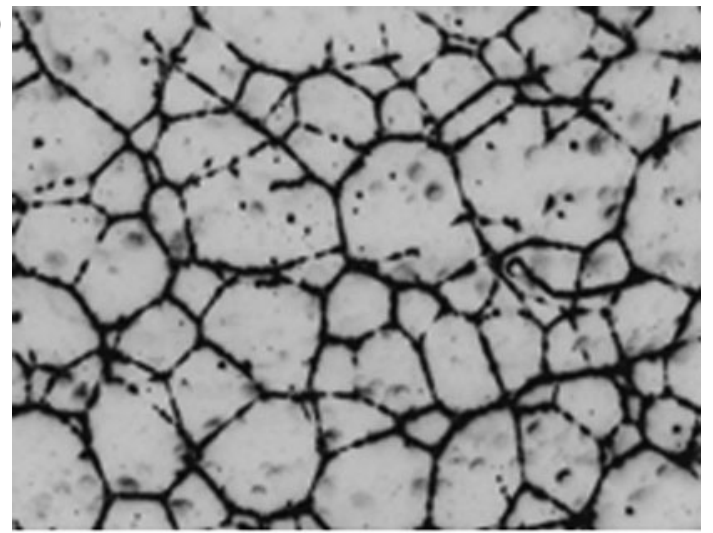

(b)

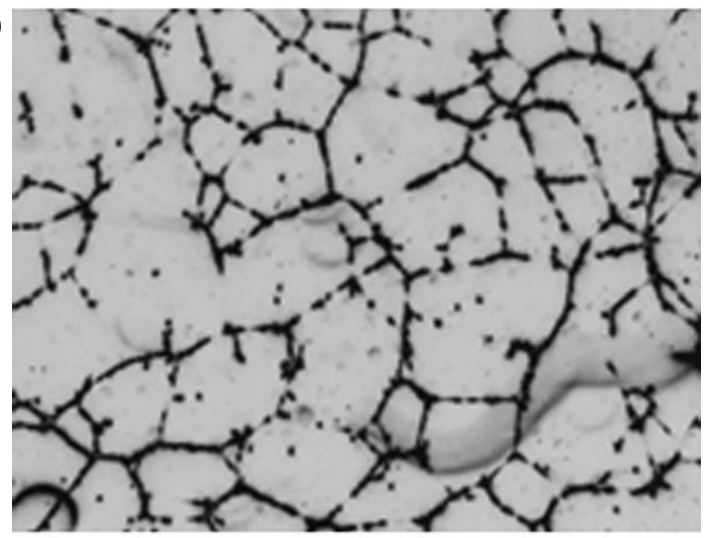

(c)

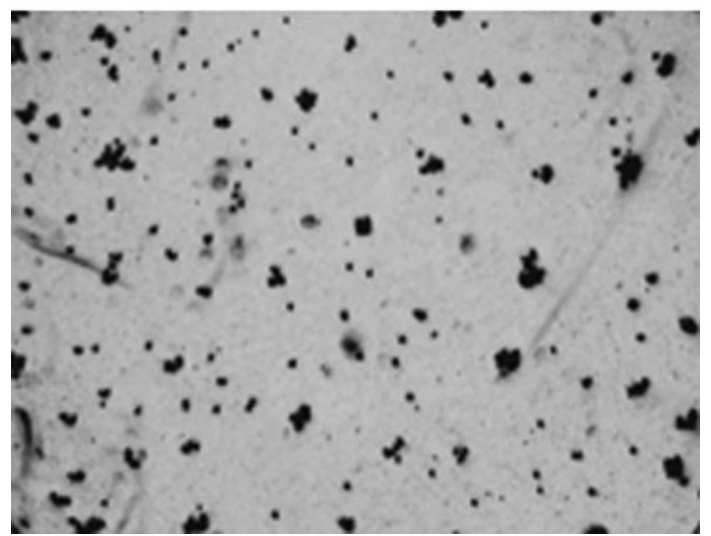

Fig. 4. (a) The pseudotubule network in an untreated control well. Effect of (b) $2.3 \mu \mathrm{mol} / \mathrm{l}$ lycopene and (c) $20 \mu \mathrm{g} / \mathrm{l}$ suramine on angiogenesis of human umbilical vein endothelial cells is shown. 

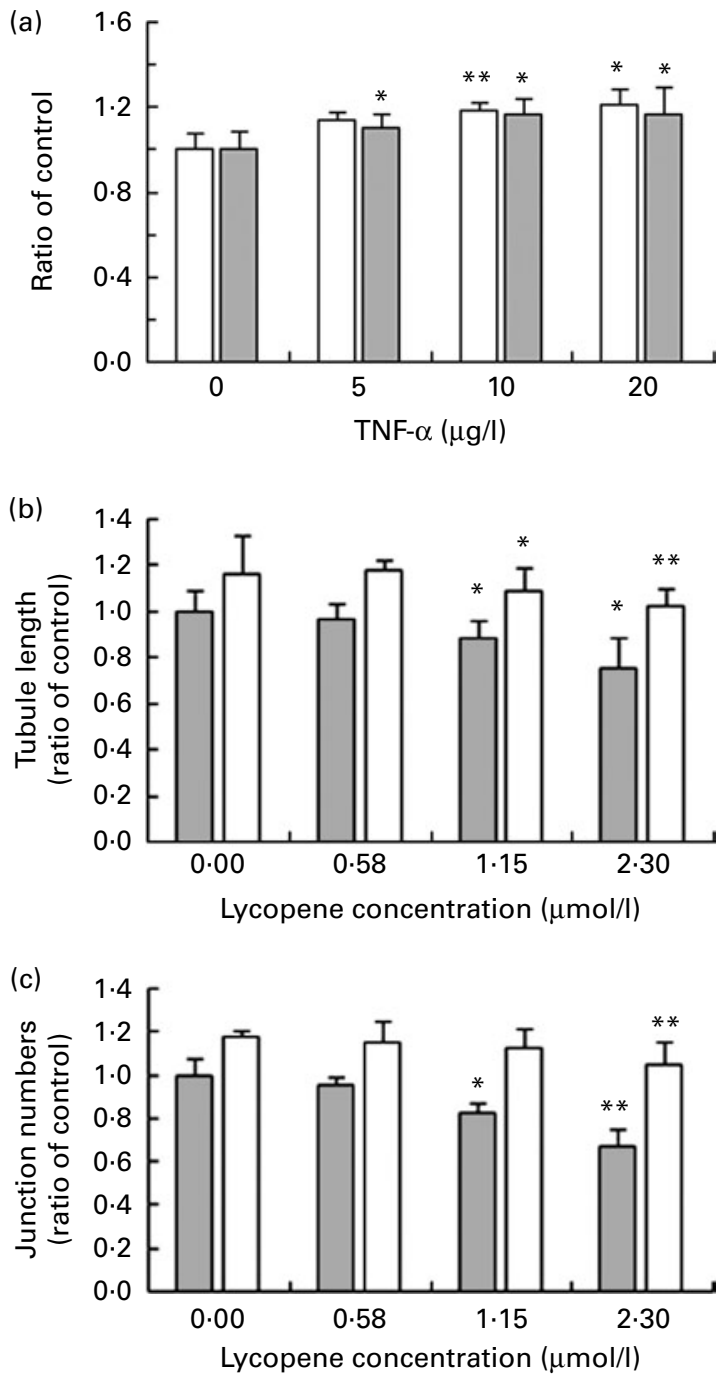

Fig. 5. The effect of TNF- $\alpha$ on angiogenesis of human umbilical vein endothelial cells. (a) Cells were treated with increasing concentrations of TNF- $\alpha$ for $24 \mathrm{~h}$ before seeding onto Matrigel ${ }^{\mathrm{TM}}$. Total tubule length ( $\square$ ) and junction numbers $(\square)$ are shown as a percentage of the control values and standard deviations. The effect of lycopene on (b) total tubule length, (c) junction numbers, both in the presence ( $\square$ ) and absence ( $\square$ ) of TNF- $\alpha$ are shown. The bar chart shows the ratio of the control values and standard deviations. Mean values were significantly different from control: ${ }^{\star} P<0.05,{ }^{\star \star} P<0.01$.

\section{Effect of vascular endothelial growth factor and lycopene on angiogenesis}

HUVEC were exposed to increasing concentrations of VEGF at concentrations of $1,2,4$ and $8 \mathrm{ng} / \mathrm{l}$, either $24 \mathrm{~h}$ before or while seeding onto Matrigel ${ }^{\mathrm{TM}}$. An increase in overall tubule length, as well as tubule numbers and junction numbers, could be observed with VEGF exposure, as is illustrated in Fig. 6. Overall tubule length peaked at $4 \mathrm{ng} / \mathrm{l}$ VEGF with a $12 \%$ increase, whereas VEGF at $8 \mathrm{ng} / 1$ resulted in an overall increase in tubule and junction numbers of approximately $20 \%$ (Fig. 6(a)). There was no significant difference in the effect of VEGF on the angiogenic activity of HUVEC pre-treated with VEGF for $24 \mathrm{~h}$ compared to exposure to VEGF upon seeding onto Matrigel ${ }^{\mathrm{TM}}$ (results not shown).
Pre-incubation of HUVEC with lycopene for $24 \mathrm{~h}$ prior to exposure of cells to $8 \mathrm{ng} / \mathrm{l}$ VEGF resulted in a reduction of both tubule length and junction numbers. Exposure of HUVEC to the lowest lycopene concentration of $0.58 \mu \mathrm{mol} / 1$ abrogated the stimulatory effect of VEGF on both the junction numbers and overall network length, but results
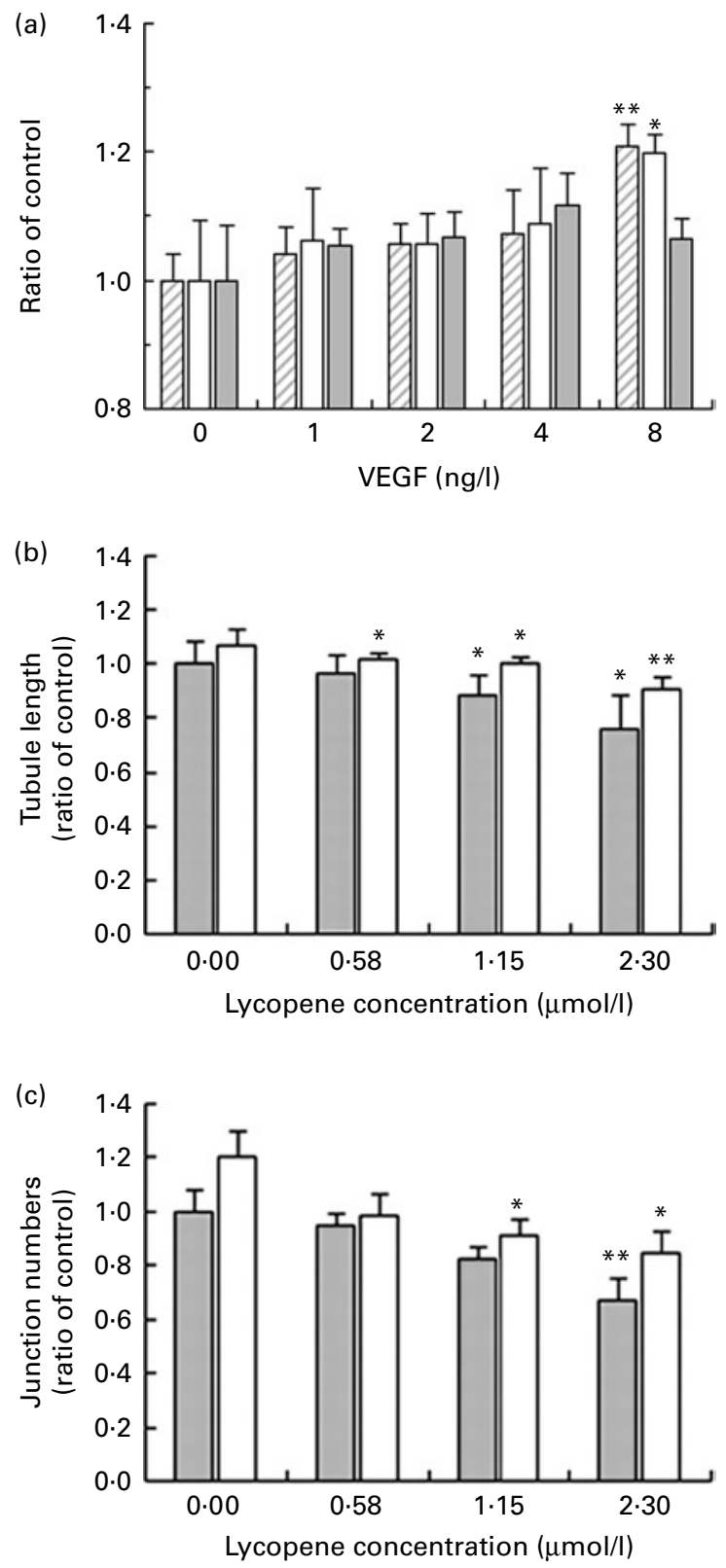

Fig. 6. The effect of vascular endothelial growth factor (VEGF) on angiogenesis of human umbilical vein endothelial cells (HUVEC). (a) Cells were exposed to increasing concentrations of VEGF upon seeding onto Matrigel ${ }^{\mathrm{TM}}$. The bar chart shows the number of tubules ( $\square$ ), junctions ( $\square$ ) and total tubule length ( $\square$ ) as a ratio of the control values and standard deviations. The effect of lycopene alone and lycopene $+8 \mathrm{ng} / \mathrm{l}$ VEGF on angiogenesis of HUVEC is shown in (b) and (c). Cells were pre-treated with increasing concentrations of lycopene for $24 \mathrm{~h}$ and exposed to $8 \mathrm{ng} / \mathrm{l}$ VEGF upon seeding onto Matrigel ${ }^{\mathrm{TM}}$. The effect of lycopene on (b) total tubule length and (c) junction numbers, both in the presence $(\square)$ and absence $(\square)$ of VEGF. Data points are presented as a ratio of the control values and standard deviations. Mean values were significantly different from control: ${ }^{\star} P<0.05,{ }^{\star \star} P<0.01$. 
were statistically significant for tubule length only $(P=0 \cdot 05)$. With increasing lycopene concentrations, both parameters decreased further (Fig. 6(b) and (c)), resulting in a maximum reduction of tubule length by $15 \%$ at $2.3 \mu \mathrm{mol} / 1(P=0.008)$ and $7 \%$ at $1.15 \mu \mathrm{mol} / 1(P=0.03)$ lycopene relative to the untreated control. The reduction in junction numbers was more pronounced at $2 \cdot 3 \mu \mathrm{mol} / 1$ lycopene (29\% reduction, $P=0.03$ ) than at $1.15 \mu \mathrm{mol} / 1$ ( $24 \%$ reduction, $P=0.05)$. Lycopene appeared to have a greater inhibitory effect on the network branching, that is, junction numbers, mediated by exposure to VEGF than on the overall tubule length.

\section{Discussion}

Tumours can remain dormant for years, during which time their size is maintained by a balance between apoptosis and proliferation of cells. This, however, maintains the tumour size at the limit for simple diffusion of nutrients and gases like $\mathrm{CO}_{2}$ and $\mathrm{O}_{2}$. To increase its growth, tumour cells secrete angiogenic factors, which lead to the recruitment of endothelial cells and their proliferation for neovascularisation. Anti-angiogenic intervention is therefore considered important in cancer interception because of the crucial role that neovascularisation plays in the pathology of cancer. In the present investigation, lycopene at a final concentration $\geq 1 \cdot 15 \mu \mathrm{mol} / 1$ significantly inhibited the angiogenic process in all the test systems, that is, rat aortic ring assay as well as TNF- $\alpha$ - and VEGF-stimulated angiogenesis in HUVEC. To extrapolate these results to an in vivo situation, it is important to consider whether the endothelium is likely to be exposed to such concentrations in vivo. Both inter-individual differences in response and bioavailability from different tomato products will overall influence the changes in plasma lycopene after supplementation $^{(15,16)}$. Plasma levels of up to $1.2 \mu \mathrm{mol} / \mathrm{l}$ have been obtained with the use of supplements at a dose of $15 \mathrm{mg}$ lycopene/d (equivalent to $600 \mathrm{~g}$ of raw tomatoes or $100 \mathrm{~g}$ of tomato paste) for 3 months ${ }^{(17)}$. A similar increase in plasma lycopene was observed after the consumption of $200 \mathrm{~g}$ tomato soup plus $230 \mathrm{~g}$ canned tomatoes providing approximately $46 \mathrm{mg}$ lycopene/d for 1 week $^{(14)}$. An increase in plasma lycopene to approximately $1.2 \mu \mathrm{mol} / 1$ has also been reported after supplementation with tomato saucebased pasta for 3 weeks providing approximately $30 \mathrm{mg}$ lycopene/ $\mathrm{d}^{(18)}$. However, several other studies with supplements or foods containing a lycopene content of $6-25 \mathrm{mg}$ and a duration period ranging from 1 to 8 weeks have shown a maximum increase of plasma lycopene to $0 \cdot 80 \mu \mathrm{mol} / \mathrm{l}^{(19-22)}$. It is therefore important to note that, although levels of up to $1.2 \mu \mathrm{mol} / 1$ can be achieved in vivo, these levels are likely to be achieved when individuals are either supplemented for a longer period of time or with high concentrations of a more bioavailable form of lycopene. In our previous study, when participants were allowed to choose from different red fruits and vegetables providing approximately $45 \mathrm{mg}$ lycopene/d, mean plasma lycopene concentrations were raised to $0.85 \mu \mathrm{mol} / 1$ only, and the change was lower in smokers compared to non-smokers ${ }^{(23)}$. Lycopene bioavailability is known to vary between tomato products, and bioavailability is higher from processed tomatoes compared to raw tomatoes ${ }^{(19,24,25)}$. Both processing and presence of fat have been show to increase the bioavailability of lycopene ${ }^{(25)}$. However, prolonged heating can also reduce the carotenoid content, especially if peeled tomatoes are used ${ }^{(26)}$. Furthermore, the lycopene content of tomato products can also vary ${ }^{(27)}$. Observational studies have reported a reduction in risk of cancer incidence, especially that of prostate cancer, with the consumption of approximately $200 \mathrm{~g}$ tomato products per day $^{(28)}$. An increase in plasma lycopene to $0.55 \mu \mathrm{mol} / 1$ has been reported with the consumption of $300 \mathrm{~g}$ raw tomatoes for $7 \mathrm{~d}$ and up to $0.80 \mu \mathrm{mol} / \mathrm{l}$ with consumption of $60 \mathrm{~g}$ tomato puree ${ }^{(19)}$. In a prospective study, patients with aggressive prostate cancer were reported to show a plasma lycopene concentration of $356 \mathrm{ng} / \mathrm{ml}(0.66 \mu \mathrm{mol} / \mathrm{l})$ compared to controls with plasma values of $388 \mathrm{ng} / \mathrm{ml}(0 \cdot 72 \mu \mathrm{mol} / \mathrm{l})^{(29)}$. In our present study, at a test concentration of $0.58 \mu \mathrm{mol} / 1$, very little effect was observed on angiogenesis. Also, we did not examine the effect within a concentration range of $0 \cdot 58-1 \cdot 15 \mu \mathrm{mol} / \mathrm{l}$. However, it is possible that a small increment in the concentration of lycopene $>0.6 \mu \mathrm{mol} / \mathrm{l}$ might have shown a significant effect and perhaps highlighted the minimum lycopene concentration that is likely to intercept the angiogenic process. Baseline plasma concentrations of $0.50-0.60 \mu \mathrm{mol} / 1$ (equivalent to the lowest concentration used in the present study) has been reported by several studies $^{(14,18,19,30)}$; however, few studies have also reported plasma levels of lycopene as low as $0.34 \mu \mathrm{mol} / 1$ with their habitual diet ${ }^{(20,21)}$. Likewise, low lycopene levels reported for cancer patients and controls also vary between studies ${ }^{(29,31-33)}$. The amount of lycopene that may be required to affect angiogenesis in vivo is therefore likely to vary between individuals. It is therefore difficult to speculate on the amount of tomato products that can be recommended for a possible angiogenic interception in vivo. The results of our study therefore can only highlight that at a baseline concentration that has been reported by several studies, that is, $0.58 \mu \mathrm{mol} / 1$, lycopene has a minimal effect on angiogenesis; however, $>1 \mu \mathrm{mol} / 1$ lycopene can significantly inhibit angiogenesis in vitro.

$\beta$-Carotene and lycopene are the two major carotenoids in tomatoes as well as in human plasma ${ }^{(18,19,23,27)}$. In one study, oral $\beta$-carotene supplementation of mice at $0.25 \%$ concentration for 2 weeks is reported to inhibit angiogenesis evoked by HeLa and SKv-t tumour cell lines, but increased the angiogenesis induced by lymphocytes ${ }^{(34)}$. Another study examined a concentration range of $0.3-3 \mu \mathrm{mol} / 1$ of $\beta$-carotene and reported an increase in basic fibroblast growth factorinduced angiogenesis in a mouse Matrigel ${ }^{\mathrm{TM}}$ model at a concentration of $3 \mu \mathrm{mol} / 1$ of the carotenoid ${ }^{(35)}$. In contrast, there are reports of a dose-dependent inhibition of tumour-specific angiogenesis in HUVEC and rat aortic rings by $\beta$-carotene at concentration range of $1-10 \mu \mathrm{g} / 1(1 \cdot 8-18 \mu \mathrm{mol} / \mathrm{l})$ in vitro $^{\text {(36) }}$ as well as in an in vivo mouse model ${ }^{(37)}$. A recent study reported a dose-related inhibition of angiogenesis by lycopene in HUVEC at a concentration range of $1-10 \mu \mathrm{mol} / \mathrm{l}^{(38)}$. In agreement with their results, our experiments also show an inhibitory effect at concentrations $>1 \mu \mathrm{mol} / \mathrm{l}$ and a small, though mostly insignificant, effect at concentrations as low as $0.58 \mu \mathrm{mol} / 1$. In the study by Sahin et al. ${ }^{(38)}$, HUVEC were 
grown in a medium supplemented with VEGF and fibroblast growth factor, and both these are considered important angiogenic growth factors. Angiogenesis inhibitors can either act by inhibition of the formation of these growth factors or through blocking of their action ${ }^{(12)}$. In the previous studies, in vivo supplementation of lycopene was shown to reduce the plasma levels of $\mathrm{VEGF}^{(11)}$ and inhibit the VEGF expression by nude mice injected with tumour cells ${ }^{(37)}$. VEGF levels are reported to be raised in cancer patients ${ }^{(39)}$. The present study has demonstrated a slight but significant reduction in VEGF-mediated angiogenesis of HUVEC after $24 \mathrm{~h}$ pretreatment of cells with lycopene, both with regard to overall pseudotubule network length and junction numbers. These effects were seen at concentrations as low as $1.15 \mu \mathrm{mol} / \mathrm{l}$, but were most pronounced at the higher concentration of $2 \cdot 3 \mu \mathrm{mol} / 1$ of lycopene.

The pro-inflammatory cytokine, TNF- $\alpha$, has also been shown to act as an autocrine growth factor for tumour angiogenesis $^{(40)}$ and to affect the angiogenesis process directly ${ }^{(40,41)}$ as well as through its effects on VEGF formation ${ }^{(41,42)}$. The present study has demonstrated angiogenesis interception by lycopene in both TNF- $\alpha$-mediated (Fig. 5(b) and (c)) as well as VEGF-induced angiogenic potential of HUVEC (Fig. 6(b) and (c)). With circulating levels of TNF- $\alpha$ being raised in prostate cancer ${ }^{(43,44)}$, lycopene might be beneficial in reducing the pro-angiogenic action of TNF- $\alpha$ in these patients. Epidemiological prospective data and dietary case-control studies suggest that a high intake of tomatoes and tomato-based products, with a resulting high plasma concentration of circulating lycopene, is associated with a highly significant reduction in the risk of cancer, in particular prostate cancer $^{(45)}$. This has been found to be especially true for the more aggressive forms of prostate cancer. Also, lower serum and prostatic tissue levels of lycopene were demonstrated in men with prostate cancer when compared to healthy age-matched controls ${ }^{(29,46)}$. Likewise, lower plasma lycopene levels have been reported in patients with cervical cancer $^{(31,32)}$ and colorectal adenomas ${ }^{(47)}$. The anti-angiogenic activity of lycopene is therefore a likely candidate not just for prostate but also for other cancers owing to the crucial role that angiogenesis plays in growth and sustainment of tumours. It has been suggested that agents that exhibit both anti-angiogenic as well as anti-metastatic activity are likely to evoke a greater effect on tumour response/therapy than treatment with a single agent of these classes ${ }^{(48)}$. The results of the present study combined with previously published anti-metastatic effects of lycopene ${ }^{(49-51)}$ not only support the findings of observational studies that show an inverse correlation between tomato consumption and risk of cancer but also offer a therapeutic hope for cancer inhibition.

Angiogenesis is a fundamental step in the transition of tumours from a quiescent to a malignant state, and is a requirement for both tumour progression and metastasis ${ }^{(52)}$. The tumour vasculature has been identified as a strong prognostic marker for tumour grading ${ }^{(53)}$. Endothelial cells represent a suitable target for anti-angiogenic treatment because they are non-transformed host cells and unlikely to acquire resistance to treatment compounds. Being part of the circulatory system, they also facilitate administration of a given therapeutic agent. Natural products are an attractive option for tumour interception, especially if they can be shown to intercept the tumorigenic processes at biologically achievable concentrations. The present investigation has demonstrated an inhibitory effect of lycopene on the angiogenic response in HUVEC and rat aortic rings at concentrations possible to be achievable in vivo after tomato product consumption. As lycopene was shown to exhibit its anti-angiogenic effects at achievable concentrations in vivo, it indeed can be regarded as a promising anti-angiogenic compound and can also explain why this compound has been highlighted as an important anti-cancer dietary component. Further in vivo studies are however warranted to confirm the in vitro effects of lycopene seen in the present study.

\section{Acknowledgements}

The authors would like to thank DSM Nutrition Products Limited for their generous gift of the crystalline lycopene used in the present study. The study was partly funded by HJ Heinz Limited (Hayes, Middlesex, UK). S. E. was supported by funding from the Institute of Biomedical and Biomolecular Science (IBBS, Portsmouth, Hampshire, UK). M. C. directed the present research and was responsible for preparing and submitting the manuscript. A. C. was the co-supervisor on the present project and helped S. E. with the rat aortic rings assay. S. E. conducted the experiments and wrote the methods and results section. All three have contributed towards the preparation of this paper. The authors declare no conflict of interest.

\section{References}

1. Dvorak HF (1986) Tumors: wounds that do not heal. Similarities between tumor stroma generation and wound healing. $N$ Engl J Med 315, 1650-1659.

2. Nagy JA, Brown LF, Senger DR, et al. (1989) Pathogenesis of tumor stroma generation: a critical role for leaky blood vessels and fibrin deposition. Biochim Biophys Acta $\mathbf{9 4 8}$, 305-326

3. Ziegler RG (1989) A review of epidemiological evidence that carotenoids reduce the risk of cancer. J Nutr 119, 116-122.

4. Giovanucci E (1999) Tomatoes, tomato-based products, lycopene, and cancer: review of the epidemiologic literature. J Nat Cancer Inst 91, 317-331.

5. Rao AV \& Agarwal S (2000) Role of antioxidant lycopene in cancer and heart disease. J Am Coll Nutr 19, 563-569.

6. Levy J, Bosin E, Feldman, et al. (1995) Lycopene is a more potent inhibitor of human cancer cell proliferation than either $\alpha$-carotene or $\beta$-carotene. Nutr Cancer 24, 257-266.

7. Rehman A, Bourne LC, Halliwell, et al. (1999) Tomato consumption modulates oxidative DNA damage in humans. Biochem Biophys Res Commun 262, 828-831.

8. Karas M, Amir H, Fishman D, et al. (2000) Lycopene interferes with cell cycle progression and insulin-like growth factor I signaling in mammary cancer cells. Nutr Cancer 36, 101-111.

9. Hwang ES \& Lee HJ (2006) Inhibitory effects of lycopene on the adhesion, invasion and migration of SK-Hep1 human hepatoma cells. Exp Biol Med (Maywood) 231, 322-327. 
10. Pennathur S, Maitra D, Byun J, et al. (2010) Potent antioxidant activity of lycopene: a potential role in scavenging hypochlorus acid. Free Rad Biol Med 49, 205-213.

11. Yang H-M, Yen Y-T, Uang C-S, et al. (2011) Growth inhibitory efficacy of lycopene and $\beta$-carotene against androgenindependent prostate tumor cells xenografted in nude mice. Mol Nutr Food Res 55, 606-612.

12. Bhat TA \& Singh RP (2008) Tumor angiogenesis - a potential target in chemoprevention. Food Chem Toxicol $\mathbf{4 6}$ 1334-1345.

13. Auerbach R, Lewis R, Shinners B, et al. (2003) Angiogenesis assays: a critical review. Clin Chem 49, 32-40.

14. Lee A, Thurnham DI \& Chopra M (2000) Consumption of tomato products with olive oil but not sunflower oil increases the antioxidant activity of plasma. Free Rad Biol Med 29, 1051-1055.

15. Porrini M \& Riso P (2005) What are typical lycopene intakes? J Nutr 135, 2042S-2045S.

16. Maiani G, Caston MJP, Catasta G, et al. (2009) Carotenoids: actual knowledge on food sources, intakes, stability and bioavailability and their protective role in humans. Mol Nutr Food Res 53, S194-S218.

17. Olmedilla B, Granado F, Southon S, et al. (2002) A European multicentre, placebo controlled supplementation study with $\alpha$-tocopherol, carotene-rich palm oil, lutein or lycopene: analysis of serum responses. Clin Sci 102, 447-456.

18. Porrini M, Riso P \& Testolin G (1998) Absorption of lycopene from single or daily portions of raw and processed tomatoes. Br J Nutr 80, 353-361.

19. Richelle M, Bortlik K, Liardt S, et al. (2002) A foodbased formulation provides lycopene with the same bioavailability to humans as that from tomato paste. $J$ Nutr 132, 404-408.

20. Porrini M, Riso P, Brusamolino A, et al. (2005) Daily intake of a formulated tomato drink affects carotenoid plasma and lymphocyte concentrations and improves antioxidant protection. Br J Nutr 93, 93-99.

21. Kim JY, Paik JK, Kim OY, et al. (2011) Effects of lycopene supplementation on oxidative stress and markers of endothelial function in healthy men. Atherosclerosis 215, 189-195.

22. Bowen P, Chen L, Stacewicz-Sapuntzakis M, et al. (2002) Tomato sauce supplementation and prostate cancer: lycopene accumulation and modulation of biomarkers of carcinogenesis. Exp Biol Med 227, 886-893.

23. Chopra M, O'Neill ME, Keogh N, et al. (2000) Influence of increased fruit and vegetable intake on plasma and lipoprotein carotenoids and LDL oxidation in smokers and nonsmokers. Clin Chem 46, 1818-1829.

24. Gartner C, Stahl W \& Sies H (1997) Lycopene is more bioavailable from tomato paste than from fresh tomatoes. $A m \mathrm{~J}$ Clin Nutr 66, 116-122.

25. Stahl W \& Sies H (1992) Uptake of lycopene and its isomer is greater from heat-processed then from unprocessed tomato juice. J Nutr 122, 2161-2166.

26. Graziani G, Pernice R, Lanzuise S, et al. (2003) Effect of peeling and heating on carotenoid content and antioxidant activity of tomato and tomato-virgin olive oil systems. Eur Food Res Techol 216, 116-121.

27. O'Neill MEO, Carroll Y, Corridan B, et al. (2001) A European carotenoid database to assess carotenoid intakes and its use in a five-country comparative study. Br J Nutr 85, 499-507.

28. Etminan M, Takkuche B \& Cammano-Isoma F (2004) The role of tomato products and lycopene in the prevention of prostate cancer: a meta-analysis of observational studies. Cancer Epidemiol Biomarkers Prev 13, 34-35.
29. Gann PH, Ma J, Giovannucci E, et al. (1999) Lower prostate cancer risk in men with elevated plasma lycopene levels: results of a prospective analysis. Cancer Res 59, 1225-1230.

30. Paetau, Khachik F, Brown ED, et al. (1998) Chronic ingestion of lycopene-rich tomato juice or lycopene supplements significantly increases plasma concentrations of lycopene and related tomato carotenoids in humans. Am J Clin Nutr $\mathbf{6 8}$, 1187-1195.

31. van Eenwyk J, Davis FG \& Bowen PE (1991) Dietary and serum carotenoids and cervical intraepithelial neoplasia. Int J Cancer 48, 34-38.

32. Batieha AM, Armenian HK, Norkus EP, et al. (1993) Serum micronutrients and the subsequent risk of cervical cancer in a population-based nested case-control study. Cancer Epidemiol Biomarkers Prev 2, 335-339.

33. Lu Q-Y, Hung J-C, Heber D, et al. (2001) Inverse associations between plasma lycopene and other carotenoids and prostate cancer. Cancer Epidemiol Biomarkers Prev 10, 749-756.

34. Szmourlo A, Marcozak M, Rudnicka L, et al. (1991) Beta-carotene in prevention of cutaneous carcinogenesis. Acta Derm Venereol 71, 528-530

35. Dembinska-Kiec A, Polus A, Kiec-Wilk B, et al. (2005) Proangiogenic activity of beta-carotene is coupled with activation of endothelial cell chemotaxis. Biochim Biophys Acta 1740, $222-239$.

36. Guruvayoorappan C \& Kuttan G (2007) Beta-carotene inhibits tumor-specific angiogenesis by altering the cytokine profile and inhibits the nuclear translocation of transcription factors in B16F-10 melanoma cells. Integr Cancer Ther $\mathbf{6}$, $258-270$.

37. Huang CS, Liao JW \& Hu ML (2008) Lycopene inhibits experimental metastasis of human hepatoma SK-Hep-1 cells in athymic nude mice. J Nutr 138, 538-543.

38. Sahin M, Sahin E \& Gumuslu S (2011) Effects of lycopene and apigenin on human umbilical vein endothelial cells in vitro under angiogenic stimulation. Acta Histochem, (Epublication ahead of print version 5 April 2011).

39. Fuhrmann-Benzakein E, Ma AN, Rubbia-Brandt L, et al. (2000) Elevated levels of angiogenic cytokines in the plasma of cancer patients. Int J Cancer 85, 40-45.

40. Minuzzo S, Moserle L, Indraccolo S, et al. (2007) Angiogenesis meets immunology: cytokine gene therapy of cancer. Mol Aspects Med 28, 59-86.

41. Sainson RCA, Johnston DA, Chu HC, et al. (2008) TNF primes endothelial cells for angiogenic sprouting by inducing a tip cell phenotype. Blood 111, 4997-5007.

42. Malaguarnera L, Imbesi R, Di Rosa M, et al. (2005) Action of prolactin, IFN- $\gamma$, TNF- $\alpha$ and LPS on heme oxygenase- 1 expression and VEGF release in human monocytes/macrophages. Int Immunopharmacol 5, 1458-1469.

43. Nakashima J, Tachibana M, Ueno M, et al. (1998) Association between tumor necrosis factor in serum and cachexia in patients with prostate cancer. Clin Cancer Res $\mathbf{4}$, $1743-1748$.

44. Michalaki V, Syrigos K, Charles P, et al. (2004) Serum levels of IL-6 and TNF-alpha correlate with clinicopathological features and patient survival in patients with prostate cancer. Br J Cancer 90, 2312-2316.

45. Giovannucci E (2002) A review of epidemiologic studies of tomatoes, lycopene and prostate cancer. Exp Biol Med (Maywood) 227, 852-859.

46. Rao AV, Fleshner N \& Agarwal S (1999) Serum and tissue lycopene and biomarkers of oxidation in prostate 
cancer patients: a case control study. Nutr Cancer 33, 159-164.

47. Erhardt JG, Meisner C, Bode JC, et al. (2003) Lycopene, $\beta$-carotene and colorectal adenomas. Am J Clin Nutr $\mathbf{7 8}$, 1219-1224.

48. Teicher BA (1995) Angiogenesis and cancer metastases: therapeutic approaches. Crit Rev Oncol Hematol 20, 9-39.

49. Hantz HL, Young LF \& Martin KR (2005) Physiologically attainable concentrations of lycopene induce mitochondrial apoptosis in LNCaP human prostate cells. Exp Biol Med (Maywood) 135, 2119-2123.
50. Salman H, Bergman M, Djaldetti M, et al. (2007) Lycopene affects proliferation and apoptosis of four malignant cell lines. Biomed Pharmacother 61, 366-369.

51. Palozza P, Simone RE, Catalano A, et al. (2011) Tomato lycopene and lung cancer prevention: from experimental to human studies. Cancers 3, 2333-2357.

52. Cavallaro U \& Christofori G (2000) Molecular mechanisms of tumor angiogenesis and tumor progression. J Neurooncol 50, 63-70.

53. Heidenreich A, Aus G, Bolla M, et al. (2008) EAU guidelines on prostate cancer. Eur Urol 53, 68-80. 